\title{
Projeto Primeiros Passos na Ciência: rompendo barreiras sociais e estreitando laços entre a comunidade acadêmica e o Ensino Médio público
}

\author{
Adna Suelen Dorigo ${ }^{1, *}$, Allison Anjos ${ }^{1, *}$, Ana Claudia de Castro Marcato ${ }^{2, *}$, Dayane Pires-Silva ${ }^{1, *}$, Letícia Rocha

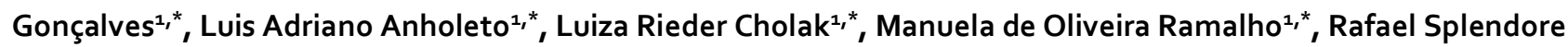 \\ de Borba $^{1, *}$, Mariana Prudenciatto Ortelani ${ }^{1}$, Diogo C. Cabral-de-Mello ${ }^{1}$
}

\begin{abstract}
Resumo: No presente trabalho, visamos ampliar discussões acerca das diferentes faces da interação Universidade-Escola, com base na apresentação de relatos de experiências sobre o Projeto Primeiros Passos na Ciência e em reflexões teóricas sobre o contexto universitário, motivadas pela prática vivenciada. O projeto em questão foi desenvolvido por alunos de pósgraduação em Ciências Biológicas (Biologia Celular e Molecular) da UNESP, Campus de Rio ClaroSP em parceria com a Escola Estadual Prof. Marciano de Toledo Piza, de ensino médio, da cidade de Rio Claro, estado de São Paulo. Este projeto teve o objetivo de introduzir o aluno do Ensino Médio no cotidiano da pesquisa universitária na área de Biologia Celular e Molecular, com a expectativa de promover a aproximação destes alunos com o desenvolvimento do conhecimento científico e o ambiente universitário. Com a realização desse projeto, a Universidade teve a chance de adentrar no contexto dos alunos de Educação Básica, mais especificamente do Ensino Médio público. Esses novos conhecimentos podem criar a possibilidade de um futuro diferente, com mais conhecimentos científicos e instigando a reflexão a partir da rotina da Universidade e seu contexto. A experiência resultou na divulgação científica, no contato do aluno do Ensino Médio com o método científico e toda a técnica e objetividade que dele derivam, ampliando os laços comunidade-universidade.
\end{abstract}

Palavras-chave: Educação; Extensão; Vivência; Experimento Científico

\section{Project First Steps in Science: breaking social barriers and strengthening ties between the academic community and public high schools}

\footnotetext{
Abstract: In the present study, we intend to expand the discussion about different approaches of the University-School interaction, based on the presentation of an account of experiences with the First Steps in Science Project and theoretical reflections on the University context motivated by the lived experience. The project in question was developed by graduate students in Biological Sciences (Cell and Molecular Biology) at UNESP, Rio Claro/SP (Brazil), in partnership with Escola Estadual Prof. Marciano de Toledo Piza a public high school in the city of Rio Claro, State of São Paulo. This project had the objective of introducing high school students to the routine of university research in the area of Cell and Molecular Biology, with the expectation of promoting the approximation of these students with the development of scientific knowledge and the university environment. With the realization of this project, the University had the opportunity to better understand the primary education context of the students, specifically within public high schools. This new knowledge can create the possibility of a different future, with more scientific properties and instigating the reflection from the routine of the University and its context. The experience resulted in scientific dissemination, high school students' contact with the scientific method, and all the technique and objectivity derived from it, expanding community-university ties.
}

Keywords: Education; Extension; Experience; Scientific Experiment
Originais recebidos em

28 de fevereiro de 2019

Aceito para publicação em 03 de março de 2020

1

Universidade Estadual Paulista (UNESP), Instituto de Biociências, Câmpus Rio Claro

2 Universidade Estadual Paulista (UNESP), Instituto de Biociências, Câmpus Rio Claro marcatoacc@gmail.com (autora para correspondência)

* Os autores compartilham a autoria principal do artigo 


\section{Introdução}

A Universidade pública tem responsabilidade com a comunidade em que se insere, sendo necessária uma postura ativa dos seus estudantes, pesquisadores, docentes e funcionários, para a evolução conjunta da instituição universitária e da comunidade externa. Para tanto, os projetos de extensão são possibilidades eficientes para criação de vínculos e redes de troca entre a comunidade universitária e a sociedade das localidades nas quais estão instaladas, dando um novo olhar para a Ciência, colaborando, assim, para melhor formação e inclusão de um público que, muitas vezes, não entende o papel acadêmico no contexto social e econômico do país, abrindo oportunidade para uma relação mais harmoniosa de ensino e aprendizagem.

Os projetos de extensão permitem que os processos de democratização e socialização aconteçam de forma efetiva, gerando novas possibilidades de intercâmbio de conhecimento e experiências entre dois segmentos, a Universidade pública e a comunidade, abrindo caminhos para que essa mesma comunidade possa, no futuro, ingressar na Universidade. Na estrutura universitária brasileira, balizada nos pilares de ensino, pesquisa e extensão, recai ao terceiro pilar a consolidação das trocas efetivas entre a instituição universitária e a sociedade que a mantém. Nesse sentido, a extensão se consolida como elemento articulador dos processos de ensino e mecanismo de divulgação dos trabalhos de pesquisa, servindo diretamente à sociedade com programas específicos.

Segundo De Paula (2013), a Universidade enfrenta dificuldades em aceitar a extensão como parte fundamental do Ensino Superior, sendo necessários uso de inter e transdisciplinaridade na condução de projetos, perfil intelectual aberto ao diálogo e alteridade. Além disso, Mendonça e Silva (2002) acrescentam que somente uma pequena parcela da população do Brasil possui acesso à Universidade pública, onde projetos de extensão contribuem para a democratização do conhecimento e cumprem a função social que a universidade deve exercer. Assim, é importante enfatizarmos a necessidade da quebra da visão racionalista de que o conhecimento é unilateral e produzido pela e para a ordem, perdendo-se, portanto, a finalidade cooperativa da educação (Azevedo \& Cunha, 2013), aspecto esse fortemente trabalhado na extensão universitária.

No contexto atual, a universidade tem como uma das funções contribuir para a solução, ou ainda auxiliar na construção de base para a resolução, dos problemas sociais por meio de políticas públicas participativas e emancipadoras. Tal função se comprova com a crescente recomendação de órgãos financiadores/ universidades na promoção de eventos de extensão que tenham como objetivo integrar a universidade com a comunidade, visando resolver ou amenizar necessidades mútuas.

Ainda assim, ações que visam estreitar os laços entre a universidade e a comunidade muitas vezes enfrentam resistências, pois não são comuns ao cotidiano dos envolvidos. Partindo desta vivência, elaboramos um Projeto de ensino e extensão que proporcionasse atividades empíricas em Biologia, buscando promover a troca de experiências e o engrandecimento do conhecimento científico de todos os participantes, sendo o "Projeto Primeiros Passos na Ciência" o fruto de tal proposta, resultado do trabalho de alunos e docentes do Programa de Pós-graduação em Ciências Biológicas - Biologia Celular e Molecular - da Universidade Estadual Paulista "Júlio de Mesquita Filho" - UNESP de Rio Claro, São Paulo, e tendo como eixo norteador a importância da aproximação da Universidade com a escola pública, e aproximação do jovem com o desenvolvimento do trabalho científico.

O Projeto ocorreu no período de 4 a 8 de junho de 2016 e possibilitou que alunos do terceiro ano da Escola Estadual Prof. Marciano de Toledo Piza, da cidade de Rio Claro-SP, entrassem em contato com o desenvolvimento do conhecimento científico - com ênfase em Biologia Celular e Molecular. 


\section{Interação Universidades públicas e o Ensino Médio de escolas públicas}

A pesquisa é uma condição necessária na construção do conhecimento e fundamentada nos processos de ensino e aprendizagem, e seus resultados se efetivam com a promoção dos processos de ensino e extensão. É premissa básica das Universidades desenvolver o processo de pesquisa, conforme preconiza a Lei de Diretrizes e Bases da Educação Nacional (LDB), de 1996, no seu art. 43, inciso III. A pesquisa como produção de conhecimento no Ensino Médio é uma prática pouco utilizada por professores e alunos, e isso traz implicações tanto na aprendizagem, como na relação dos alunos com o contexto universitário e, consequentemente, nas relações de trabalho que nele se desenvolvem.

O referencial teórico adotado (Cunha, 2009) aponta a necessidade de reavaliação das práticas pedagógicas no contexto universitário e ressalta a conquista da interdisciplinaridade nos processos de ensino, pesquisa e extensão como um dos maiores desafios das universidades brasileiras. Enquanto a pesquisa e o ensino têm sido alvo de discussões, a extensão universitária, em contrapartida, não recebeu a mesma ênfase nem sofreu as transformações necessárias em ritmo e intensidade pertinentes para acompanhar a evolução do Ensino Superior (Silva \& Vasconcelos, 2006).

A formação do aluno de graduação e/ou de pós-graduação vai além da aquisição de conhecimentos técnicocientíficos, até porque esses se esvaziam quando são construídos de maneira alheia às transformações sociais. Para uma abordagem inovadora, a aprendizagem deve ir além da aplicação imediata, impulsionando o sujeito a criar e responder a desafios, ser capaz de gerar tecnologias e manter a habilidade de aprender e recriar permanentemente o conteúdo científico apreendido, ou seja, a graduação deve ser o período de produção do conhecimento, em que o aluno atue como sujeito da aprendizagem (Fórum de Pró-Reitores de Extensão das Universidades Públicas Brasileiras, 2001). Como defende o Fórum de Pró-Reitores das Universidades Públicas Brasileiras, na formação do profissional é imprescindível sua interação com a comunidade para situá-lo historicamente, identificá-lo culturalmente e referenciar a sua formação técnica à realidade.

Logo, devemos compreender que as universidades não constituem organizações isoladas, para assim desconstruirmos a premissa comum na qual a extensão se consolida como "mecanismo de devolução para a sociedade". É importante compreendê-la como condição essencial, nos modelos universitários brasileiros, para a efetivação de ações de ensino superior que sejam contextualizadas, e em consequência, transformadoras da sociedade em que se desenvolvem. A parceria entre a Universidade e escola pública por meio de projetos e atividades de pesquisa, ensino e extensão, é um importante caminho no processo de concretização de estratégias de formação. Chassot (2003) aponta a alfabetização científica como uma abordagem emergente no ensino de ciências e de extrema importância para que os jovens compreendam a ciência como linguagem e consigam "decifrar" seu conhecimento associado. Muito mais do que um meio de corrigir informações passadas de maneira errônea e leviana por meios de comunicação que visam atingir o público leigo, a alfabetização científica permite que o público se torne menos vulnerável aos erros das notícias divulgadas. Além disso, a alfabetização científica tem um importante papel na inclusão social. $O$ autor defende que a alfabetização científica, além de ser um agente facilitador da inclusão social que permite a leitura e o entendimento da natureza por parte dos alunos, também permite a eles entender a necessidade de transformação desse mundo natural - por meio da tecnologia e da ciência em si - e dessa modificação para o bem, para algo melhor.

Observando que o viés prático de fazer ciência, em geral, é algo praticamente restrito àqueles que a produzem, nosso objetivo com o projeto "Primeiros Passos na Ciência" é justamente auxiliar na quebra da "barreira" entre a escola e ambiente universitário e científico, buscando a democratização do mesmo. O desenvolvimento do projeto é focado em alunos da rede pública como forma de tentar atendê-los no âmbito da inclusão social, da 
alfabetização científica e do fornecimento de uma possibilidade de experiência, tanto no sentido da experimentação prática e objetiva quanto no plano dos sentidos. Segundo Schnetzler (1998), a formação de parcerias possibilita o confronto das teorias educacionais com os problemas e as características das práticas pedagógicas usuais dos professores do ensino básico, contribuindo gradativamente para a reformulação das mesmas. Dessa forma, o estabelecimento de articulações efetivas entre a Universidade e a escola pública pode ajudar na promoção de círculos de democratização do conhecimento, estabelecendo uma relação dialética entre ação e teoria, que beneficiaria o processo de formação de ambas as instituições.

\section{O Ensino de Ciências}

Ensinar Ciências é um grande desafio, tanto pela complexidade dos conteúdos como pelo constante e rápido avanço de conhecimento nas diversas áreas. As descobertas científicas, principalmente no campo da Biologia Molecular, Genética e Biotecnologia, envolvendo temas polêmicos como clonagem, uso de células-tronco e organismos transgênicos, são presentes na vida contemporânea. De acordo com Pedrancini et al. (2007), essas pesquisas têm gerado grandes discussões acerca dos benefícios, riscos e das implicações que o uso dessas tecnologias pode trazer para a sociedade. Diante dessa realidade, torna-se essencial que a formação científica seja um componente central da Educação Básica, contribuindo para a formação de futuros cidadãos, dotados de senso crítico e socialmente ativos (Malafaia \& Rodrigues, 2008).

O cotidiano escolar muitas vezes é pautado pelo ensino tradicional e traz o ensino de ciências como verdade incontestável, sem possibilidades de contradição ou interferência. A renovação dos processos educativos, bem como o crescimento de novas tendências pedagógicas pautadas na aprendizagem ativa e na valorização da participação do aluno em seus processos de aprendizagem auxiliam na paulatina alteração do cenário tradicionalista, possibilitando a efetivação de práticas nas quais os conteúdos deixem de ser vistos como informativos e passem a ser vistos como formativos. Com esse novo pensar, as atividades práticas tornaramse recursos facilitadores para a compreensão do ensino de ciências (Leite et al., 2013).

O ensino de Ciências e Biologia nas escolas públicas deveria possibilitar aos alunos construir, refletir, ressignificar e assimilar os conhecimentos e não os substituir por ideias de senso comum (identificadas inclusive, entre estudantes universitários) (Mortimer, 1996; Pedrancini et al., 2007). A dificuldade do aluno em relacionar a teoria desenvolvida em sala com a realidade a sua volta, bem como o ensino voltado somente à memorização de conceitos, são os grandes responsáveis por dificultar a aprendizagem significativa (Sobral \& Siqueira, 2007). Na visão dos discentes, a Biologia pode ser uma das disciplinas mais relevantes, atraentes e merecedoras da atenção, porém, se conduzida de forma desinteressante e pouco compreensível, utilizando teorias complexas, torna-se difícil para o aluno refletir sobre o que aprendeu (Krasilchik, 2004).

Delizoicov et al. (2013) destacam que a maioria dos professores da área de Ciências permanece seguindo os livros didáticos, insistindo na memorização de informações isoladas, acreditando na importância dos conteúdos tradicionalmente explorados e na exposição como forma principal de ensino, esquecendo que a parte prática é ferramenta fundamental para a internalização do conhecimento pelos alunos. As teorias científicas se mostram complexas e com alto nível de abstração, ficando muitas vezes distantes da compreensão dos alunos do Ensino Básico. Parece evidente que o modo como o ensino é organizado e conduzido é pouco eficaz em promover o desenvolvimento conceitual. Dessa forma, é essencial que o ensino de Ciências e Biologia se adapte à maneira como o raciocínio se desenvolve, enfatizando o aprendizado ativo por meio do envolvimento dos estudantes em atividades de descoberta (Krasilchik, 2004).

Segundo Freire (1993), a realização de experimentos é uma excelente ferramenta para o desenvolvimento prático dos conteúdos, possibilitando que os alunos estabeleçam uma relação dinâmica e indissociável entre contexto e conteúdo. A importância da experimentação no processo de aprendizagem é discutida por Bazin 
et al. (1987), destacando que uma experiência de ensino não formal de Ciências aposta na maior significância desta metodologia em relação à simples memorização da informação - método tradicionalmente empregado nas salas de aula. Em tal perspectiva, ressaltamos no presente trabalho a necessidade de promoção de práticas no ensino de ciências que possibilitem a articulação entre a esfera das ações científicas de produção do conhecimento com as esferas didáticas de produção e divulgação do conhecimento científico - que poderão ser efetivadas tanto na Educação Básica quanto no Ensino Superior.

\section{Primeiros Passos na Ciência: ressignificando as dimensões de "experiência"}

Tomando como referência o ensino de Biologia, pesquisas sobre a formação de conceitos têm demonstrado que estudantes da etapa final da Educação Básica apresentam dificuldades na construção do pensamento crítico neste campo do conhecimento. A maioria dos estudantes destes níveis de ensino apresentam ideia sincrética, portanto, pouco definida, sobre célula, confundindo este conceito com os de átomo, molécula e tecido (Bastos, 1992; Senabre \& Giménez, 1993, Giordan \& Vecchi, 1996). Diante dessa realidade, parece evidente que o modo como o ensino é organizado e conduzido está sendo pouco eficaz em promover o desenvolvimento conceitual.

A educação, enquanto campo de produção do conhecimento, tem sido separada historicamente nos binômios teoria/prática e ciência/técnica. Bondía (2002), em seu trabalho "Notas sobre a experiência e o saber da experiência", propõe a exploração outra possibilidade pedagógica, para além dos pares discutidos. $O$ autor propõe que pensemos a educação segundo o par experiência/sentido. Bondía (2002, p. 21) define a experiência como aquilo que nos toca, sendo necessariamente os acontecimentos que passam por nós e em nós ficam: "Nunca se passaram tantas coisas, mas a experiência é cada vez mais rara". Ele frisa que informação não é o mesmo que experiência, portanto, o excesso dela nada significa nesse âmbito. $O$ sujeito que busca a informação se anula enquanto sujeito que experimenta, na busca incessante pelo saber: "[...] uma sociedade constituída sob o signo da informação é uma sociedade na qual a experiência é impossível" (Bondía, 2002, p. 22). O saber obtido com a experiência, ou seja, conseguido por meio do que nos acontece, é um saber subjetivo, individual. Assim, duas pessoas distintas submetidas à mesma situação terão experiências diferentes. Essas considerações devem ser tomadas quando trabalhamos a experimentação com jovens, pois cada experiência é única e cada um é atingido de uma maneira. O fundamental é fazer com que, independentemente de como a experiência é sentida pelo indivíduo, que seja positiva e enriquecedora.

Nesse mesmo trabalho, Bondía (2002, p. 23) faz uma crítica à ciência, se referindo à forma como a mesma transformou a experiência - esfera dos sentidos - em experimento - este da esfera da objetividade -, promovendo uma aprendizagem fundamentada no acúmulo de verdades objetivas em detrimento do saber que nos toca.

A escola é, nos dias de hoje, um elemento passivo da globalização. Por essa razão, não é mais a única construtora de conhecimento, que antes detinha. Agora, o mundo entra nas escolas e altera a forma de educar. Antes, o nível de conhecimento dos alunos era medido pela quantidade de conhecimento - mesmo que na forma de conteúdos decorados - que possuíam. Por sua vez, a medida de qualidade para os professores da escola era a quantidade de material didático acumulado no dia a dia.

Com isso, devemos nos questionar sobre o quanto precisamos buscar uma ciência da escola, ou seja, o quanto é necessário elaborarmos novamente a concepção de ciência e os conhecimentos preexistentes, de forma que se adequem à escola e às suas necessidades sociais específicas. Esse questionamento é polêmico quando se discute a formação dos professores de Ciências.

Reafirma-se, neste sentido, a dimensão da alfabetização científica explicitada por Chassot (2003), e se valida a necessidade de uma experimentação com os alunos, saindo do ambiente da escola e entrando no ambiente 
universitário e, mais profundamente, no ambiente científico, como tentativa de rompermos a visão distanciada da ciência e do mundo.

Assim, o projeto Primeiros Passos na Ciência se consolida como uma ação extensionista da pós-graduação em Biologia Celular e Molecular da UNESP, objetivando a expansão das práticas formativas no espaço universitário, bem como a ressignificação das dimensões de "experiência" - visando à aproximação com os escritos de Bondía (2002) - para todos os sujeitos envolvidos na atividade.

\section{Metodologia}

\section{Planejamento e estruturação do projeto}

Frente ao exposto, com uma grande adesão, alunos e docentes do Programa de Pós-Graduação idealizaram este projeto com o objetivo de minimizar a distância entre a universidade e o Ensino Médio da rede pública.

Após diversas reuniões, o aceite das supervisoras pedagógicas e diretoras foi obtido. E em conjunto com as professoras de Biologia da escola pública, foram elaborados os planos das atividades de cada curso oferecido, tendo como base o conteúdo programático abordado em sala de aula pelas professoras. A intenção sempre foi pensar na forma mais dinâmica e natural para abordar as diferentes temáticas oferecidas nos cursos, sempre focando na integração dos estudantes com os alunos de pós-graduação, com os laboratórios de pesquisa e a universidade como um todo. Por essa razão, ficou definido no cronograma que o primeiro dia de curso seria uma atividade de vivência no campus.

Oito cursos foram desenvolvidos em seus núcleos centrais para receber os alunos interessados em participar do projeto. Para o processo de seleção, o aluno deveria escrever uma redação/carta explicitando os motivos pelos quais gostaria de participar do projeto e em quais cursos teria interesse. Os alunos tiveram um período de 15 dias para a elaboração e escrita das redações, que foram entregues à organização para análise. Os organizadores dividiram as cartas pelos cursos de interesse e, a partir desta divisão, foi realizada a seleção, com a divulgação do resultado na escola participante. Cada curso teve um aluno inscrito. Os alunos selecionados e seus respectivos responsáveis assinaram um termo de consentimento de participação e autorização de direito de uso de imagem, devido à preparação e à posterior divulgação da apresentação em vídeo para a comunidade e também na internet.

Ademais, na programação também foi reservado um tempo, de aproximadamente 4 horas, para o aluno de cada curso elaborar um vídeo de três minutos, com fotos e áudios (opcionais), mostrando e relatando as atividades desenvolvidas, bem como sobre a importância desse projeto a partir da sua experiência.

A mobilidade dos estudantes entre a escola e a universidade, assim como a alimentação dos mesmos, durante a semana, foi responsabilidade da organização. A semana foi dividida em três diferentes etapas: a) Apresentação da universidade a todos os participantes; b) Os alunos participaram das atividades dos grupos pré-selecionados e c) Foi realizado um encerramento, aberto a toda comunidade, com a apresentação dos vídeos previamente confeccionados. Os vídeos foram depositados no Canal da Pós-Graduação no Youtube; os links e mais informações sobre os cursos oferecidos estão no material suplementar.

\section{Conhecendo a Universidade}

A semana do evento começou com a recepção dos estudantes e uma visita ao campus da UNESP de Rio Claro. Os monitores acompanharam os oito estudantes nessa visita com o objetivo de deixá-los à vontade com o ambiente universitário, apresentando um pouco de alguns dos cursos superiores oferecidos no campus e seus respectivos espaços, na tentativa de dar-Ihes uma perspectiva da variedade de conhecimento que a 
Universidade pode oferecer, além de proporcionar uma experiência mais interessante e dinâmica. Visitamos o museu de Paleobiologia e visitamos as criações de insetos sociais, conhecendo primeiro o meliponário e os ninhos de cupins e depois os formigueiros mantidos no Centro de Estudos de Insetos Sociais. Os estudantes puderam ter contato direto com esses animais e aprenderam um pouco sobre a Biologia deles. Por último, preparamos uma exposição de vertebrados taxidermizados e artrópodes, para que eles pudessem ver diferentes grupos de animais e tirassem eventuais dúvidas.

\section{Desenvolvimento dos Cursos}

Após a finalização do primeiro dia de atividade, os alunos foram alocados nos cursos por eles escolhidos, nos quais realizaram atividades variadas ao longo da semana. Os cursos oferecidos foram: Unidade e diversidade: a célula de perto; Venenos Animais; A Sociedade das Formigas - Um universo incrível a poucos passos de você; Inseticidas naturais e seus efeitos nos tecidos e comportamentos de cupins; Acessando o código genético; Mutagênese; Genética e estudos cromossômicos em insetos e Impacto do uso de inseticidas em Abelhas.

\section{Resultados e Discussão}

\section{Relatos de experiências}

Os resultados observados se pautam na divulgação do conhecimento científico por meio das atividades práticas realizadas, como a produção dos vídeos, além da troca de experiências entre os alunos de pósgraduação e os discentes das escolas (relatadas a seguir; mais detalhes sobre os cursos e vídeos no material suplementar). Esta última apresentou-se como um resultado inesperado, porém positivo, na qual há um claro estreitamento de laços entre comunidade e universidade (Figura 1). Os resultados foram apresentados por meio dos relatos das vivências de cada curso oferecido.

\section{Unidade e diversidade: a célula de perto}

O curso introduziu a aluna na área da Biologia Celular pela abordagem de conceitos básicos e demonstrações práticas da teoria aprendida em sala de aula. Durante o curso, a estudante teve contato com diferentes metodologias de estudo, como visualização ao microscópio óptico de diferentes tipos de tecidos, identificação de organelas, núcleo, material genético e extração de DNA (ácido desoxirribonucleico).

No primeiro dia de curso a aluna participou de exposições teóricas dos conteúdos referentes à Biologia Celular e microscopia, sendo então encaminhada para o Laboratório de Histologia, onde aprendeu a forma correta de manusear microscópios, analisar lâminas com células procariontes e eucariontes e também cromossomos mitóticos de vertebrados (peixes e anfíbios).

Após essas práticas, a aluna foi direcionada para o Laboratório de Citogenética Animal, onde foram apresentados os equipamentos utilizados. Neste momento, foram discutidos temas de Biologia Molecular referente à estrutura da molécula de DNA, técnicas de extração de DNA, PCR (reação em cadeia da polimerase) e visualização de DNA no gel de agarose. Também foi ensinado um método simples de extração de DNA de morangos que é facilmente reproduzido fora do laboratório, por necessitar apenas de materiais que podem ser adquiridos em supermercado (álcool, detergente neutro e morango). 


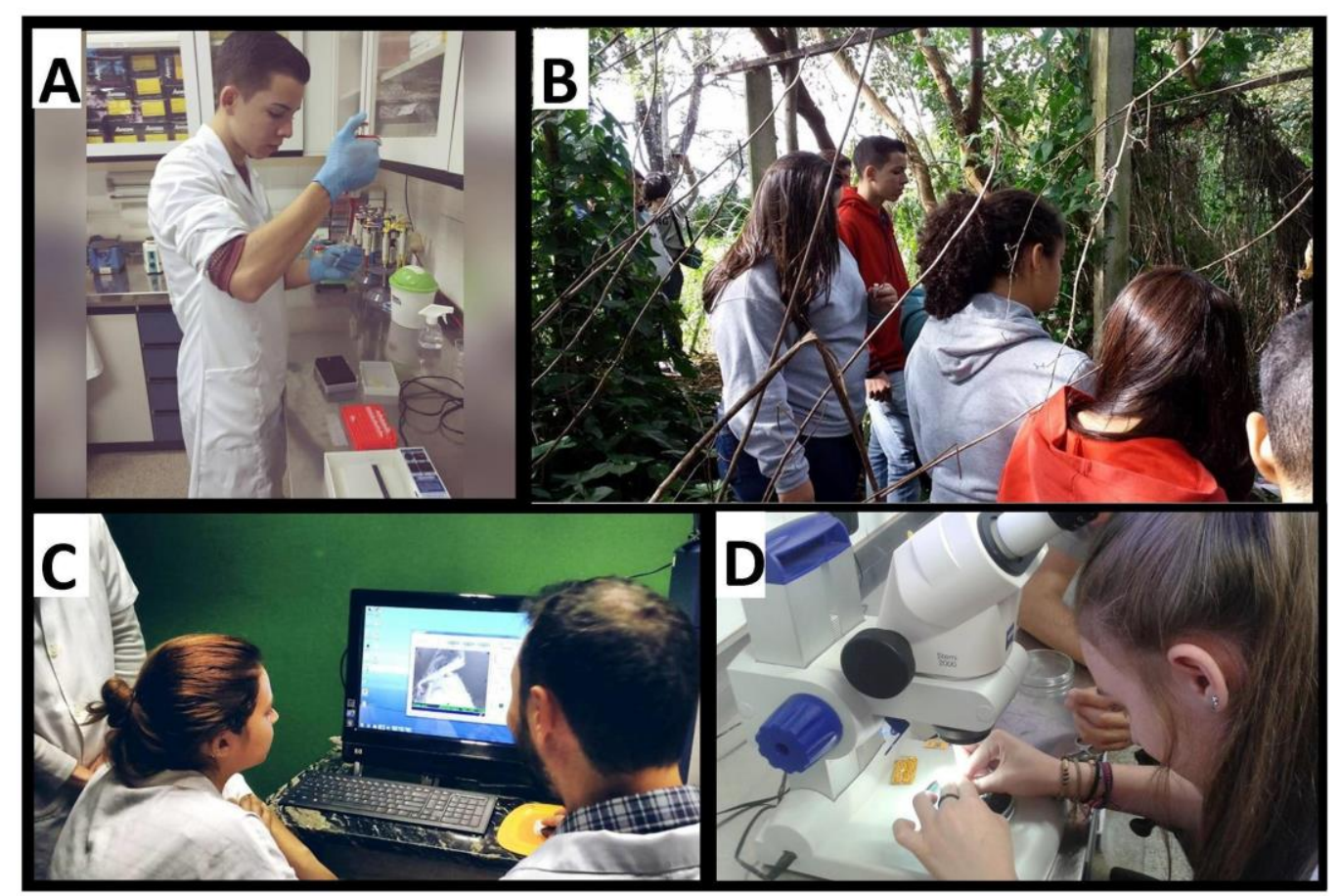

Figura 1. Exemplos de atividades oferecidas aos alunos de Ensino Médio da rede pública no projeto Primeiros Passos na Ciência. Todas as atividades foram elaboradas e guiadas por uma equipe altamente especializada dos alunos de pós-graduação da Biologia Celular e Molecular da UNESP de Rio Claro-SP. A. Práticas de biologia molecular. B. Coletas de campo. C. Práticas no laboratório de microscopia eletrônica. D. Técnicas de dissecção.

\section{Venenos animais}

O objetivo principal do curso foi compreender a importância dos venenos na biologia e na evolução das espécies animais, onde a aluna entendeu a complexidade estrutural dos venenos e suas toxinas. A estudante pôde aprender mais sobre a biologia dos animais peçonhentos comuns como: aranhas e vespas. Foram abordados ainda técnicas de identificação desses animais em seus ambientes naturais, coleta, comportamento, hábitos de alimentação, técnicas de capturas de presa, teias e tipos de veneno.

Após identificados, foi possível o aprendizado das técnicas de dissecação do reservatório de veneno do animal e com o extrato, realizou a análise das proteínas ali presentes, através de técnicas de proteômicas e cromatografias. Por meio de análises de bioinformática, a aluna identificou as principais proteínas presentes no veneno da vespa e relacionou com sua função, além da importância da composição química e estrutural como o estudo de diversas moléculas do veneno (proteínas, peptídeos e baixa massa). A aluna manuseou diversos equipamentos e realizou vários procedimentos tendo a oportunidade de aprender de forma atrativa e dinâmica sobre a importância da estruturação de uma molécula de proteína e a aplicação direta na sua função. A estudante foi desafiada a montar uma molécula identificada no veneno da vespa, levando em consideração sua estrutura tridimensional e com o auxílio de material didático de peças montáveis. Ao final da semana, a aluna descreveu que adorou a experiência. 


\section{A sociedade das formigas - Um universo incrível a poucos passos de você!}

A jovem, que relatou estar em um laboratório pela primeira vez, aprendeu mais sobre os insetos sociais de uma maneira geral, levando em consideração a biologia e o comportamento deste grupo de animais. Foram ensinadas técnicas de coleta em campo, identificação dos ninhos e espécies distintas em seu ambiente natural. Com a imensa diversidade de formigas coletadas, a estudante obteve conhecimento básico sobre taxonomia. Foi abordada a importância da montagem de coleções entomológicas e dos museus. Ela teve contato com rotinas de laboratório de biologia molecular, onde retomou conceitos aprendidos em sala de aula como DNA e estruturação celular. Por meio de técnicas de dissecção, a aluna conseguiu reconhecer distintos órgãos, obtendo conhecimento sobre a morfologia interna de insetos.

Após a identificação das principais formigas que podem causar dano econômico à sociedade, a estudante pôde realizar a manutenção destes ninhos mantidos em laboratório. Para além disso, ela auxiliou em testes que buscam medidas alternativas de controle desses animais, quando considerados pragas, podendo com isso vivenciar e discutir toda a problemática ambiental acerca do uso de agrotóxicos em monoculturas. Além disso, temas que levam em consideração o método científico, muitas vezes, são pouco empregados no Ensino Médio, e a aluna pôde entender a importância da experimentação e obtenção do significado biológico. Correlacionar temas aprendidos em sala de aula com práticas em laboratório foi um objetivo atendido com êxito pelo projeto.

\section{Inseticidas naturais e seus efeitos nos tecidos e comportamentos de cupins}

O objetivo do projeto foi comparar o efeito de dois inseticidas naturais, óleo de cravo e de laranja, nos cupins, observando o comportamento e as alterações externas ao corpo do inseto. Para tal, a aluna precisou conhecer biologia geral dos insetos sociais e especificamente sobre cupins, incluindo conhecimentos sobre a identificação de espécies e ninhos dos gêneros Coptotermes, Nasutitermes e Cornitermes em seus ambientes naturais. Após a coleta, foi feita a identificação das diferentes castas presentes dentro de uma colônia de cupins. A aluna aprendeu sobre a importância da manutenção e acondicionamento desses ninhos em laboratório, e a sua biologia geral como comportamento, preferências alimentares, tempo de vida, etc.

Estabelecida a metodologia, a aluna foi capaz de aplicar o método científico. Os resultados obtidos confirmaram que o óleo de cravo tem efeito inseticida maior quando comparado com o óleo de laranja. Após essa etapa, a estudante aprendeu a utilizar a lupa para conferir os danos externos e internos causados ao inseto pela aplicação do inseticida, por meio de técnicas de dissecação.

\section{Acessando o código genético}

O objetivo do curso foi observar e identificar espécies de formigas-cortadeiras em seu ambiente natural, posteriormente realizando a coleta para a extração do material genético da formiga para aplicação das técnicas de biologia molecular. As atividades iniciaram com as observações dos ninhos de formigas-cortadeiras, em que o aluno pôde distinguir as castas (soldados, operárias e jardineiras), entendendo a dinâmica da sociedade de formigas e sua interação com o fungo mutualista, identificando algumas possíveis espécies por aspectos morfológicos (cor, tamanho e odor) e, por fim, coletar alguns indivíduos para iniciar as atividades de biologia molecular.

Antes da extração do DNA, foram retomados alguns assuntos já estudados pelo aluno no Ensino Médio, como estruturas e funções celulares, estrutura e função do DNA e RNA (ácido ribonucleico), onde o estudante foi se familiarizando também, por meio de abordagem teórica, com as práticas de biologia molecular. Após um 
treinamento, o estudante teve facilidade em manusear todos os equipamentos, inclusive aqueles que exigem muita concentração e precisão, ficando surpreso com a sua capacidade de "fazer ciência". Após foi realizada a extração do DNA de morango, pois o resultado é visível e a simplicidade da técnica possibilitou que o aluno levasse essa prática para fora do laboratório.

Em seguida, o aluno pôde ver e participar de técnicas de eletroforese, PCR, e o sequenciamento genético. Todas as atividades realizadas permitiram que o aluno tivesse contato com o que é fazer pesquisa de biologia molecular e sentir que a ciência pode estar perto de sua realidade, sendo capaz de produzi-la, pela facilidade nas práticas e também com a bagagem teórica adquirida.

\section{Mutagênese}

O curso teve o intuito de apresentar os mecanismos relacionados ao DNA de organismos vivos, bem como as mutações que o mesmo pode sofrer em decorrência de exposição à poluição. A estudante teve a oportunidade de rever os conceitos teórico, seguidos da realização da parte prática do curso.

Foram ensinadas normas de segurança para a estudante, que pela primeira vez esteve presente - e atuante em um laboratório. A aluna realizou atividades como o manuseio de cultura celular de hepatoma humano, linhagem C3A, mantidas em sistemas bidimensionais (2D) e também trabalhou com o bioindicador vegetal Allium cepa (cebola). Foi realizada a prática de manuseio da cultura celular, além de diferentes metodologias, como marcação de citoesqueleto em células hepáticas humanas, visualizado em microscópio de fluorescência. Foi praticado o ensaio de teste de aberrações cromossômicas em que as sementes de $A$. cepa foram expostas a um agente contaminante para visualização do material genético após a formação de radículas. $O$ agente contaminante utilizado foi uma amostra de água do lago presente no Instituto de Biociências da UNESP de Rio Claro.

Posteriormente, os resultados experimentais foram visualizados em microscópio óptico para observação de aberrações cromossômicas no material exposto. Com as observações pôde-se discutir o conteúdo teórico com a aluna, possibilitando maior compreensão da temática. Assim, a estudante teve conhecimento da rotina de um laboratório de mutagênese ambiental e o mais importante, viveu a prática investigativa e a avaliação dos resultados obtidos.

\section{Genética e estudos cromossômicos em insetos}

O curso teve como principal objetivo entender a organização, a estrutura e o comportamento nas divisões celulares dos cromossomos dos insetos, componentes das células relacionados ao armazenamento e transmissão da informação genética. Após se familiarizar com os espaços físicos do departamento, a aluna teve um treinamento sobre normas que devem ser seguidas ao se trabalhar em um laboratório de pesquisa. Em seguida, aprendeu os diferentes insetos estudados no laboratório (gafanhotos, cigarrinhas, grilos, percevejos, besouros e abelhas), aprendendo sobre a biologia, o comportamento e a importância ecológica desses animais.

Após uma breve introdução sobre DNA e sua organização, a estudante aprendeu como utilizar os folículos testiculares dissecados dos gafanhotos e cigarrinhas para confeccionar as preparações cromossômicas e analisá-las ao microscópio, e depois de ver as diferentes fases da divisão celular, a aluna pôde aprender na prática como é realizado o procedimento de extração de DNA dos insetos. Por fim, dando início às análises de genética molecular, a aluna aprendeu sobre as diferentes classes de sequências de DNA que compõem os cromossomos e realizou a técnica de hibridização in situ fluorescente. 


\section{Impacto do uso de inseticidas em Abelhas}

As aulas ministradas durante todo o curso tiveram como objetivo mostrar como é o cotidiano de um laboratório e de um projeto de pesquisa. A aluna acompanhou os alunos de pós-graduação e iniciação científica em suas atividades e realizou com os mesmos várias atividades práticas, nas quais foram explicados os conceitos principais dos trabalhos com as abelhas e os inseticidas. A estudante inicialmente aprendeu como preparar um experimento, desde a coleta dos insetos, a contaminação com inseticida (forma oral e tópica), realização das coletas de órgãos, inclusão dos mesmos, corte, coloração e análise de resultados.

As atividades realizadas possibilitaram à discente uma introdução ao mundo da ciência, mostrando a importância das abelhas para o meio ambiente e como os inseticidas agem no organismo das mesmas. Essa atividade foi de extrema importância para a troca de experiências e saberes entre as pessoas envolvidas no projeto.

Incentivar a busca pelo conhecimento e o amor às ciências sobrepõe-se à simples vontade de despertar interesse pela Biologia. O projeto contemplou a maioria das linhas de pesquisa do programa de Biologia Celular e Molecular (Biologia Molecular e Estrutural, Biologia Celular e do Desenvolvimento e Citogenética e Mutagênese). Foram organizados diferentes cursos que, em sintonia com o conteúdo programático da escola participante, puderam, além de complementar as atividades em sala de aula, demonstrar a importância e a concretização de estudos com essas temáticas.

\section{Conclusão}

Esta prática foi de grande contribuição para elucidação destes temas, visto que, na maioria das vezes, estas estruturas são apresentadas apenas na forma de esquemas ou fotos para os alunos do Ensino Médio.

O contato prático dos alunos com os conteúdos aprendidos em sala de aula é essencial para a fixação desses, além de ser um caminho para o despertar de interesse deles pelo conhecimento, pelo entendimento do mundo em que vivemos e da natureza.

O projeto por nós realizado buscou uma integração dessas diferentes interpretações da palavra "experiência", promovendo o contato do aluno de Ensino Médio com o método científico e toda a técnica e objetividade que dele derivam, porém, incentivando também a experiência enquanto sentir, tentando tocá-los de alguma forma. Essa integração se deu na forma como introduzimos o adolescente à Universidade, realizando passeios pelo campus, incentivando a observação da natureza e de toda beleza contida nela, promovendo a reflexão em todos os tópicos abordados e mostrando, por meio da prática, os novos conhecimentos que puderam ser obtidos pelas diferentes técnicas.

\section{Contribuições de cada autor}

A.S.D., A.A., A.C.C.M., D.P.S., L.R.G., L.A.A., L.R.C., M.O.R., R.S.B. participaram com contribuições intelectuais substanciais na concepção e planejamento do projeto, na articulação entre a universidade e a escola participante, na execução do projeto, redação e revisão intelectual crítica do artigo e são responsáveis pela aprovação final para publicação, diante disso, solicitamos que a primeira autoria seja compartilhada entre esses autores. M.P.O. atuou na orientação da escrita do artigo, assim como na sua revisão intelectual crítica e D.C.C.M. atuou na supervisão do projeto e na revisão do manuscrito. 


\section{Agradecimentos}

Os autores agradecem à direção do Instituto de Biociências e do Instituto de Geociências e Ciências Exatas, e a todos os coordenadores dos diferentes laboratórios de pesquisa do Departamento de Biologia e Zoologia, e do Programa de Pós-Graduação em Ciência Biológica (Biologia Celular e Molecular) da UNESP de Rio ClaroSP, por terem recebido e apoiado esse projeto.

\section{Referências}

Azevedo, M. A. R., \& Da Cunha, M. I. (2013). Formação para a docência no âmbito da pós-graduação na visão dos seus formadores. Educação Unisinos, 18(1), 97-106.

Bastos, F. (1992). O conceito de célula viva entre os alunos de segundo grau. Em Aberto, 11(55), 63-69.

Bazin, M., Costa, C., Fillipo, D., Kurtenbach, E., Sette-Câmara, M., Parcionik, S., ... \& Castro, S. L. D. (1987). Three years of Living Science in Rio de Janeiro: Learning from experience. In: Oxford University. Science literacy papers. (pp. 67-74). Oxford: University of Oxford Department for External Studies Scientific Literacy Group, 1987.

Behrens, M. A. (Org.) Docência universitária na sociedade do conhecimento. Curitiba: Champagnat, 2003.

Bondía, J. L. (2002). Notas sobre experiência e o saber de experiência. Revista Brasileira de Educação, 19, 20-28.

Chassot, A. (2003). Alfabetização científica: Uma possibilidade para inclusão social. Revista Brasileira de Educação, 22, $89-100$

Cunha, M. I. (2009). O lugar da formação do professor universitário: O espaço da pós-graduação em educação em questão. Revista Diálogo Educacional, 9(26), 81-90.

De Paula, J. A. (2013). A extensão universitária: História, conceito e propostas. Interfaces-Revista de Extensão da UFMG, 1(1), 5-23.

Delizoicov, D., Slongo, P., Inês, I., \& Lorenzetti, L. (2013). Um panorama da pesquisa em educação em ciências desenvolvida no Brasil de 1997 a 2005. Revista Electrónica de Enseñanza de las Ciencias, 12(3), 459-480.

Fórum de Pró-Reitores de Extensão das Universidades Públicas Brasileiras (FORPROEX). (2001). Plano Nacional de Extensão Universitária. Ilhéus: Editus.

Freire, A. (1993). Um olhar sobre o ensino da física e da química nos últimos cinquenta anos. Revista de Educação, 3(1), 37-49.

Giordan, A., \& Vecchi, G. de (1996). As origens do saber: Das concepções dos aprendentes aos conceitos científicos. Porto Alegre: Artes Médicas.

Jezine, E. (2004). As Práticas curriculares e a extensão universitária. In Anais do Congresso Brasileiro de Extensão Universitária, Belo Horizonte, 2. Belo Horizonte: UFMG.

Krasilchik, M. (2004). Prática de ensino de biologia. São Paulo: EDUSP.

Leite, C., Fernandes, P., \& Marques Da Silva, S. O (2013). Lugar da educação para a cidadania no sistema educativo português: perspetivas de docentes de uma escola TEIP. Educação, 36(1), 35-43.

Malafaia, G., \& Rodrigues, A. S. L. (2008). Uma reflexão sobre o ensino de ciências no nível fundamental da educação. Ciência \& Ensino, 2(2), 1-9.

Mendonça, S. G. L., \& Silva, P. S. (2002). Extensão universitária: Uma nova relação com a administração pública. In: Calderón, A. I., \& Sampaio, H. Extensão universitária: Ação comunitária em universidades brasileiras. (pp. 29-44). São Paulo: Olho D’água. 
Mortimer, E. F. (1996). Construtivismo, mudança conceitual e ensino de Ciências: Para onde vamos? Investigações em Ensino de Ciências, 1(1), 20- 39.

Pedrancini, V. D., Corazza-Nunes, M. J., Galuch, M. T. B., Moreira, A. L. O. R., \& Ribeiro, A. C. (2007). Ensino e aprendizagem de Biologia no ensino médio e a apropriação do saber científico e biotecnológico. Revista Electrónica de Enseñanza de las Ciencias, 6(2), 299-309.

Schnetzler, R. P. (1998). Contribuições, limitações e perspectivas da investigação no ensino de ciências naturais. Anais do Encontro Nacional de Didática e Pratica de Ensino - ENDIPE, Águas de Lindóia, 9. Águas de Lindóia: [s.n.].

Senabre, M. J. C., \& Giménez, I. (1993). Las ideas del alumnado sobre el concepto de célula al finalizar la educación general básica. Enseñanza de las Ciencias: revista de investigación y experiencias didácticas, 11(1), 63-68.

Silva, M. S., \& Vasconcelos, S. D. (2006). Extensão universitária e formação profissional: Avaliação da experiência das Ciências Biológicas na Universidade Federal de Pernambuco. Estudos em Avaliação Educacional, 17(33), 119 -135.

Sobral, A. D. C. S., \& De Siqueira, M. H. Z. R. (2007). Jogos educativos na aprendizagem de Paleontologia do Ensino Fundamental. Anuário do Instituto de Geociências, 30(1), 213-214.

Como citar este artigo:

Dorigo, A. S., Anjos, A., Marcato, A. C. C., Pires-Silva, D., Gonçalves, L. R., Anholeto, L. A., ... \& Cabral-de-Mello, D. C. Projeto Primeiros Passos na Ciência: Rompendo barreiras sociais e estreitando laços entre a comunidade acadêmica e o Ensino Médio público. Revista Brasileira de Extensão Universitária, 11(1), 47-59. https://periodicos. uffs.edu.br/index.php/RBEU/article/view/10768/pdf 